\title{
Conceptual Understanding of Visualizer and Verbalizer Using Multiple Representation
}

\author{
1Fariz Setyawan, ${ }^{2}$ Eka Zuliana, ${ }^{3}$ Ruzlan Md Ali \\ ${ }^{1}$ Universitas Ahmad Dahlan, Jl. Ringroad Selatan, Tamanan, Bantul, Daerah Istimewa Yogyakarta \\ 2 Primary Teacher Education, Teacher Training and Education Faculty, Universitas Muria Kudus \\ ${ }^{3}$ School of Education and Modern Languages, Universiti Utara Malaysia \\ e-mail: fariz.setyawan@pmat.uad.ac.id
}

\begin{abstract}
Students' understanding of function can be seen by their representation of symbols, words, and graphs. Students' understanding can be determined by considering their choices in defining, giving examples, and presentations of functions from the presentation choices provided for them. This study had used three types of multiple representation which comprised of symbols, words, and graphs to describe students' understandings of functions. In this descriptive qualitative research, the researchers had classified the subjects based on verbalizer learning style and visualizer learning style. Verbalizer and visualizer learning styles are forms of cognitive learning styles. Both the verbalizer and visualizer's works were described based on their preferences in representing the given functions. Their works, as well as their response sin the interviews, provided opportunities for the researchers to study their emerging understanding of mathematical concepts. The verbalizer tends to connect her understanding by detail explanation of the given representation. On the other hand, the visualizer tend to connect her imagination from a picture that represents her ideas.
\end{abstract}

Keywords: understanding, multiple representation, cognitive learning styles

How to Cite: Setyawan, F., Zuliana, E., \& Ruzlan, Md..A. (2020). Conceptual Understanding of Visualizer and Verbalizer Using Multiple Representation. International Journal on Emerging Mathematics Education, 4(2), 53-62. http://dx.doi.org/10.12928/ijeme.v4i2.17767

\section{INTRODUCTION}

National Council of Teachers of Mathematics (2000) explained that there are six principles of teaching mathematics in school, one of them is learning principle. Learning principle insists students to study mathematics using their understanding. The students should understand the concept effectively and construct their own understanding based on their experience or their previous concept. Various kinds of understanding and different types of knowledge are described in the literature: instrumental and relational understanding (Skemp, 1976), conceptual, and procedural knowledge (Hiebert \& Lefevre, 1986). There are many research which studied about students' understanding. Skemp (1978) explained that mathematics concept should be thought of with better understanding. Skemp seems to view mathematics as mental tool, and thus the acquisition of mathematics, being something that involves the mind, needs appropriate learning and teaching (Skemp, 1982). A simple model of understanding in mathematics is to view the growth of understanding as the constructing cognitive connections. (Ginsburg \& Amit, 2008; Sierpinska, 2013). More specifically, when we encounter some new experiences there is a sense in which we understand it if we can connect it to previous experiences or, better, to a network of previously connected experiences. It means that conceptual understanding derived 
based on their connection of the present and previous experiences and make classification of it.

Verbalizer and visualizer's understanding of function can be seen by their preference in describing the given representation of a function. Considering verbalizer and visualizers's thinking about a mathematical topic, allows one to better understand the broader domain of verbalizer and visualizers's mathematical thinking and its influence on teaching and learning process. Previous studies conducted by Setyawan (Setyawan, 2017) found that students' representation of a mathematical topic contributed significantly to their conceptual understanding of a linear equation in one variable (LEOV). In other words, the understanding about a mathematical topic can be determined using subject preference in describing the given representation. Representation will affect the students' understanding about a concept that he or she has learned. The student's representation can be visual, verbal, and mathematical. This process will continue to be modified in the mind of the student (Anam, Widodo, \& Sopandi, 2017).

Most studies has focused on how representations benefit students' understanding about a topic in mathematics (Anam et al., 2017; Panasuk, 2010, 2011). Functions, as one of topics in mathematics, can be seen in symbol, words, and graph representations. Within this literature, there is some aspects of the functions concept are most crucial for deep understanding. This present study identifies how verbalizer and visualizer subject make relation between representation, gives examples and nonexamples of functions, interprets functions by using multiple representation.

This study was designed to get greater depth of information concerning verbalizer and visualizer's understanding about functions. It is describing verbalizer and visualizers's perspective, especially in make relation between representation with their own beliefs, giving examples and non-examples of functions, and interpreting functions represent by symbol, words, and graph.

By investigating the relationship between students' preferences and the other tendency, Dunn, et al. (2002) mentioned that there is a relationship between learning styles and students' understanding. In addition, Wu, Dale, \& Bethel (1998) said that learning styles affect students' conceptual understanding of a concept. In this study the author will describe the relation of a specific learing styles, verbalizer and visualizer learning styles in understanding of function using multiple representation.

\section{RESEARCH METHOD}

The objective of this study are to describe firstly, the conceptual understanding verbalizer and visualizer learning styles using multiple representation. This study were conducted for $5^{\text {th }}$ semester students in Universitas Ahmad Dahlan.

The main instrument of this study is the researcher their selves. Besides, the supporting instruments are required to support the research which consist of cognitive learning styles questionnaire, conceptual understanding of Function test (TPK), and interview. Data analysis will be conducted after completing data collection. The procedures of data analysis consist of data reduction, data display, drawing conclusion, and verification (Miles, M.B. \& Huberman, 1994). Systematically, the research procedures of this study consist of three main stages namely preparation, implementation, and making report.

IJEME, Vol. 4, No. 2, September 2020, 53-62 


\section{Type of study}

The type of this study is a descriptive qualitative research. It describes the verbalizer and visualizer's understanding about Function using multiple representation such as symbol, word and graph representation.

\section{Background of the research}

This study was conducted approximately for one year and a month. The research was held in Universitas Ahmad Dahlan.

\section{Research's Participant}

The participants of the study were $5^{\text {th }}$ grade college students of Universitas Ahmad Dahlan. They were categorized based on the cognitive learning styles questionnaire result. This study involves two students, who were selected based on their cognitive learning styles, namely verbalizer and visualizer learning styles. The researchers had also considered others variables such as gender, mathematics ability, and age to be controlled.

\section{Data collection methods and Data analysis}

A cognitive learning style questionnaire designed by Blazehenkova \& Kozhevnikov (2008) was administered to the students before they start to answer the Conceptual Understanding Test (TPK). The questionnaire was validated by the first author, a lecturer in Universitas Ahmad Dahlan and a teacher in secondary school in Sidoarjo. The students were categorized based on the result of their dominant learning style, which is verbalizer or visualizer cognitive learning styles. After categorizing the students, the researchers then started to consider other variables such as gender, mathematics ability (in calculus), and their age. The other variables were controlled. A month after analysis, the first TPK was administered to the students. Subsequently, the questions were given three phases. Thus, subsequently, their answers about the conceptual understanding of the Function were also collected in three phases. In the first phase, the students were given two questions related to symbol representation. In this phase the students needed to define the Function concept in their own words, either giving examples or non-examples.

In the second phase, the students should pick out their preferences by choosing the given representations. After picking out their preferences, they needed to explain what function concept it represents and why it represents a Function concept. In the last phase, the students needed to explain the relation of the given representation using their own words. They provided their opinion of the given problems based on their preferences and their experience while studying Function in the previous experience. The interviews were used to give a deeper validation about the students' paperwork. The interviews sought to obtain in-depth answers that cannot be provided by the written test alone.

Since it was using time triangulation, the researcher continued to carry out the aforementioned phases until the data obtained was consistent and gave a complete picture of the verbalizer and visualizer's understanding of the Function concept. The interviews were audio recorded by using tape recorder. After collecting the data, the authors transcribed the interviews into text.

During the analysis stage, the first and second authors start to reconstruct the data. In each phase, the collected data were reduced until the data gave the real result for the verbalizer and visualizer's understanding of Function. Notes were immediately 
written upon the completion of each lesson to avoid from forgetting and leaving out any important details. Having a thorough description of each phase had helped in writing the general description of the situation during the analysis stage.

By using a diagram, description of situation, and symbols representation, the subject explains her understanding and perspective about Functions. The information about conceptions of visualizer's representation in Functions was obtained during the first 3 weeks of the study, using a written instrument and two interviews. Visualizer's paperwork and interviews' responses had provided opportunities to gain additional insight concerning her mathematical conceptions and the extent in which her perspective had influenced those conceptions.

Table 1. Descriptor of students' understanding using multiple representation

\begin{tabular}{|c|c|c|}
\hline No & Students Understanding & Representation \\
\hline 1. & Define functions by using own word & Word representation \\
\hline 2. & $\begin{array}{l}\text { Give example and non-example of } \\
\text { functions }\end{array}$ & Symbol represe \\
\hline 3. & $\begin{array}{l}\text { Choose appropriate representation to } \\
\text { make best use in defining functions }\end{array}$ & $\begin{array}{l}\text { Symbol, word and } \\
\text { diagram representation }\end{array}$ \\
\hline 4. & $\begin{array}{l}\text { Make relationship } \\
\text { representation }\end{array}$ & $\begin{array}{l}\text { Symbol, word and } \\
\text { diagram representation }\end{array}$ \\
\hline
\end{tabular}

Adapted from Panasuk $(2010 ; 2011)$

\section{RESULTS AND DISCUSSION \\ Description of the verbalizer's conceptual understanding}

Based on the result of the cognitive questionnaire, the subject can mostly be categorized as having a verbalizer learning style. This was confirmed after the first author asked about her preference in studying mathematics. She tends to talk actively and had explained more about her perspective based on her experience in senior high school.

Firstly, the verbalizer subject had asked the first author (observer) when she first attempted to answer the given Conceptual Understanding Test (TPK). Nevertheless, after solving it twice and third times, the verbalizer answered all of the given questions in TPK without asking the observer. Seemingly the verbalizer had defined the Function based on her own experience in school. The verbalizer's paperwork that defines the Function concept is presented in Figure 1.

1. Berikan pengertian Fungsi dengan menggunakan kata-katamu sendiri Fungsi adalah yang comainnye tidak memetakan lobih dan iatu ke codimain atay bahasa shat hanny domanya tidak selingkuh dan domainnya haru berpasangan tidak boleh kosong

Figure 1. Verbalizer paperwork in defining Function

The definition of Function is presented as the relation of one element in domain to the exactly one element in codomain (see in Figure 1). The verbalizer subject clarified that its definition is based on her memory when her teacher was given the example of a relation and mentioned that it is called as a Function. Mostly, her memory

IJEME, Vol. 4, No. 2, September 2020, 53-62 
is related to the diagram that represented the Function. Hence, function is described based on the definition which her teacher had mentioned before.

Additionally, the verbalizer had given examples and non-examples of Function as shown in Figure 2.

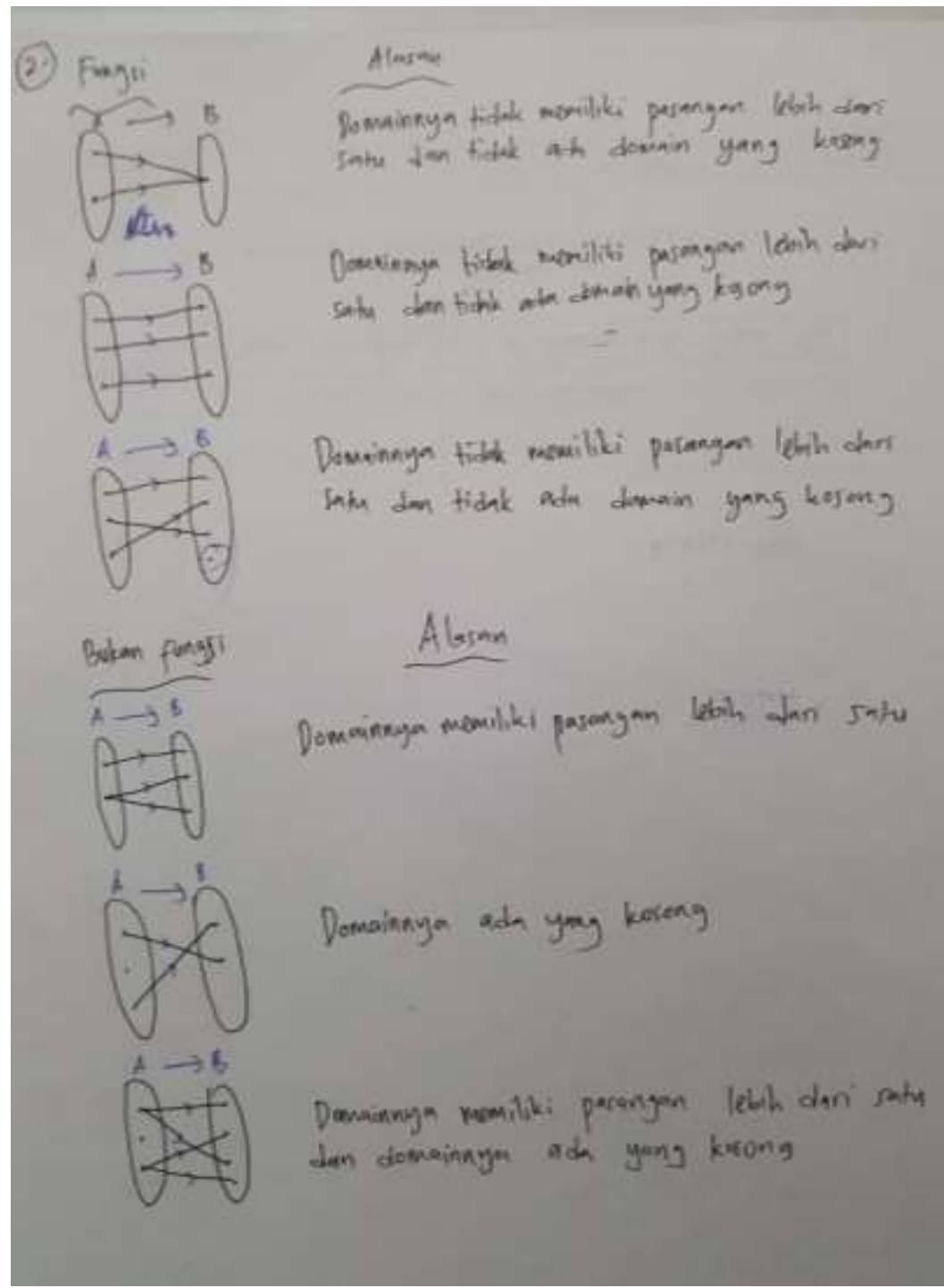

Figure 2. Verbalizer paperwork in giving examples and non-examples of Function

Mostly, the examples and non-examples of Function were presented in symbol representation. In addition, while the researcher gave an illustration of a Function using by using diagram, the verbalizer tends to remember the symbol representation rather than its pictorial diagram. In confirming her preference in symbol representation, the verbalizer was given three representations, such as symbol, word and graph representation. Each representation was well-described by the verbalizer. The verbalizer's preference for understanding of Function using multiple representation is shown in Figure 3. 


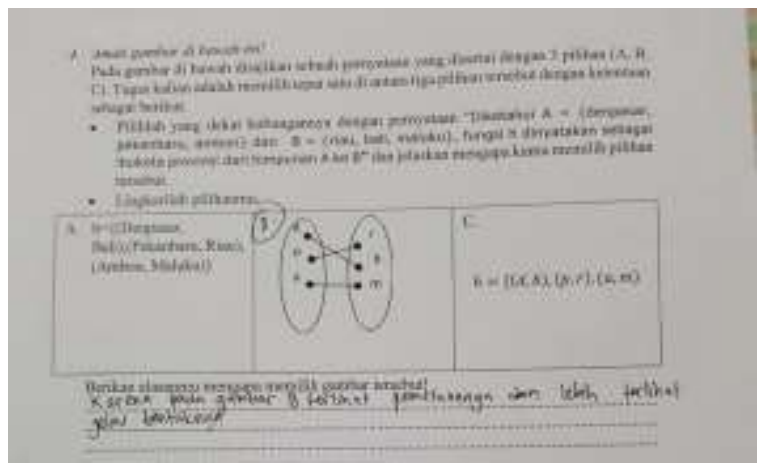

Figure 3. verbalizer paperwork in giving preference of Function representation

The verbalizer's understanding of function is described by using symbol representation rather than the other representation (see in Figure 3). The fact that the verbalizer was able to elaborate the relationship between symbol, word and graph representation had indicated her understanding of Function. The verbalizer's paperwork is shown in Figure 4.

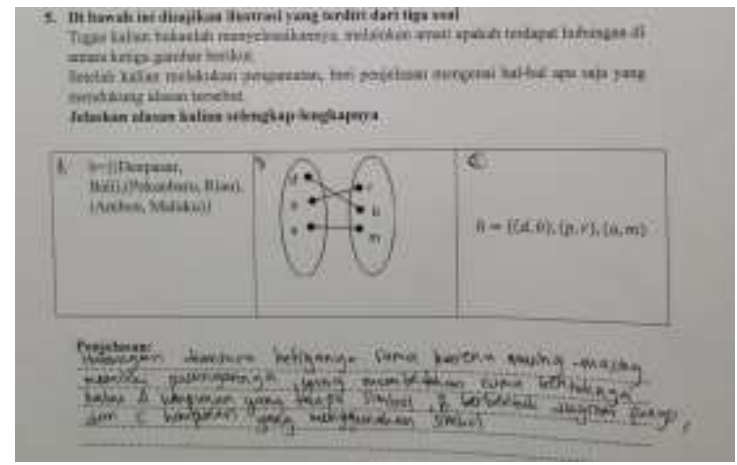

Figure 4. Verbalizer paperwork in making relationship between symbol, word and diagram representation

The relationship between three representations was described by the similarity of each symbol used in all representation. After that, the verbalizer mentioned differences based on her perception of each representation. The researcher asked the verbalizer why she had picked out the similarity of the symbol used in each representation and she had responded by saying that it was the easiest way to make the relation between figures.

Based on the result of the current study, the verbalizer tends to choose symbol representation rather than word and graph representation. She thinks that it was the easiest way to explain the concept of the Function.

\section{Description of the visualizer's conceptual understanding}

Based on the result of the cognitive questionnaire, the research subject mostly indicated characteristics of having a visualizer learning style. This was confirmed after the first author asked her preference in studying mathematics. She tends to imagine the concept. She explained more about her perspective based on her experience in class and her senior high school.

Firstly, the visualizer was asked by the first author to answer the given Conceptual Understanding Test (TPK). She answered the questions, related to the

IJEME, Vol. 4, No. 2, September 2020, 53-62 
Function, by using her perspective and demonstrating her response by using picture or diagram. The visualizer answered all of the given questions in TPK by mostly using picture and diagram representation. Additionally, the visualizer subject had also defined Function based on her experience in school. The visualizer's paperwork in giving the definition of Function is presented in Figure 5.

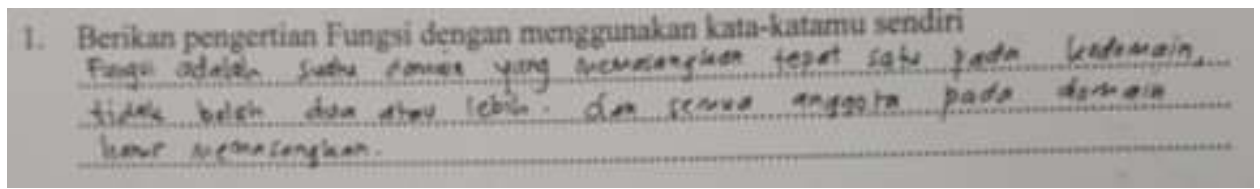

Figure 5. visualizer paperwork in defining Function

The definition of the function is presented as the relation one element in domain to the exactly one element in codomain (see in Figure 5). The visualizer subject clarified that its definition is based on her memory while her teacher gave the example of a relation and that it is called as a Function. Mostly, her memory is related to the diagram which represented the Function. Figure 6 shows the visualizer's examples and non-examples of Function.

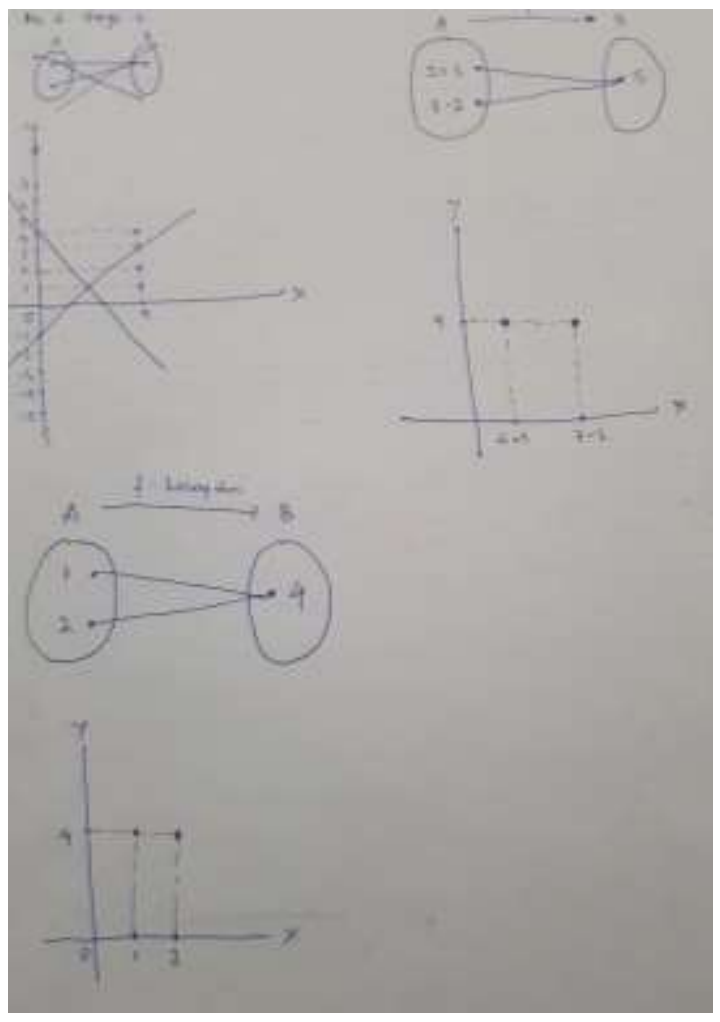

Figure 6. visualizer paperwork in giving examples and non-examples of Function

Mostly, the visualizer gave examples and non-examples of Function by presenting them using diagram and graph representation (see in Figure 6). In addition, when the researcher gave an illustration of a Function by using diagram, the visualizer tends to remember the details of the diagram representation. As a means of 
confirming her preference in graph representation, the visualizer was given three representations, such as symbol, word and graph representation. Each representation was well-described by the visualizer. The preference for the verbalizer's understanding of Function using multiple representation is shown in Figure 7.

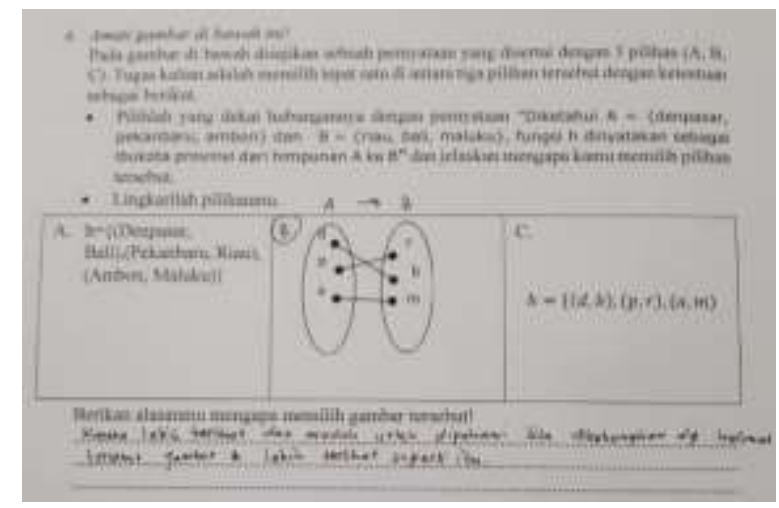

Figure 7. visualizer paperwork in giving preference of Function representation

The visualizer's understanding of function is described by using diagram and graph representation rather than the other representation (see in Figure 7). The explanation about the visualizer understanding is shown when she elaborated the relationship between symbol, word and graph representation. The visualizer's paperwork is shown in Figure 8.

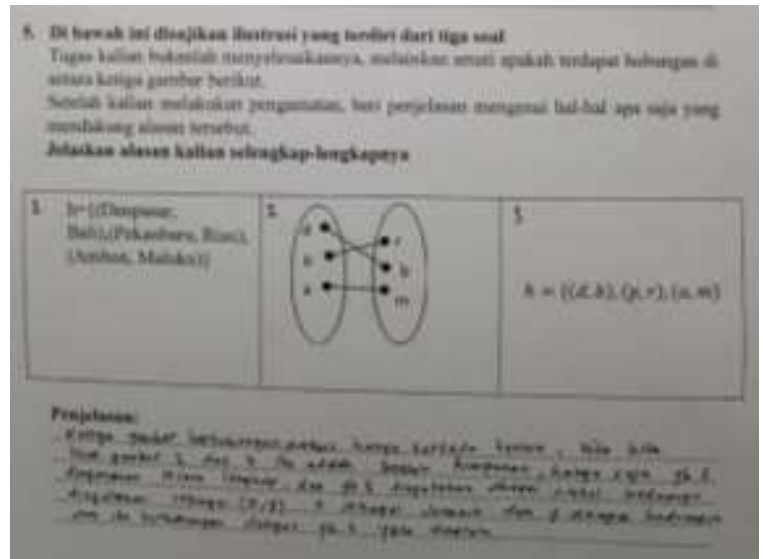

Figure 8. visualizer paperwork in making relationship between symbol, word and diagram representation

The relationship between three representations was described by the similarity of each symbol used in all the representations. After that, the visualizer described differences based on her perception of each representation. The researcher asked the subject why she had picked out the similarity of the symbol used in each representation. She answered by that it was based on her imagination to make the relation between the figures.

Based on the result of this study, seemingly the visualizer tends to choose graph representation rather than symbol and word representation. To her, it was the easiest way to explain the concept of Function.

IJEME, Vol. 4, No. 2, September 2020, 53-62 


\section{Conceptual understanding using multiple representation}

Table 2 summarizes both the verbalizer and visualizer's paperwork in representing Functions. For example, from the verbalizer's perspective, Function is seen by using symbol representation. This study has also found that the visualizer's word representation of functions is described based on the visualization of diagram representation (Setyawan, et al. 2017). Both research subjects had provided written examples and non-examples of Function using diagrams.

Table 2. Verbalizer and Visualizer Representation of Functions

\begin{tabular}{|c|c|c|}
\hline Descriptor & Verbalizer tasks & Visualizer tasks \\
\hline $\begin{array}{l}\text { Define functions by using } \\
\text { own word }\end{array}$ & $\begin{array}{l}\text { Connecting the elements of } \\
\text { domain to exactly one } \\
\text { elements of codomain }\end{array}$ & $\begin{array}{l}\text { Connecting the elements of } \\
\text { domain to exactly one } \\
\text { elements of codomain }\end{array}$ \\
\hline $\begin{array}{l}\text { Give example and non- } \\
\text { example of functions }\end{array}$ & $\begin{array}{ll}\text { Using } & \text { symbol } \\
\text { representation } & \end{array}$ & $\begin{array}{l}\text { Using } \\
\text { representation }\end{array}$ \\
\hline $\begin{array}{l}\text { Choose appropriate } \\
\text { representation to make } \\
\text { best use in defining } \\
\text { functions }\end{array}$ & $\begin{array}{l}\text { Subject's preference in } \\
\text { symbol representation }\end{array}$ & $\begin{array}{l}\text { Subject's preference in } \\
\text { diagram representation }\end{array}$ \\
\hline $\begin{array}{l}\text { Make relationship between } \\
\text { representation }\end{array}$ & $\begin{array}{l}\text { Made relationship based } \\
\text { on similarity of the } \\
\text { symbols used }\end{array}$ & $\begin{array}{l}\text { Made relationship based } \\
\text { on the shape of the given } \\
\text { data }\end{array}$ \\
\hline
\end{tabular}

The results of this current study seem to indicate to support the conjectures that students' understanding is determined by connections, strength of relationships (Hiebert \& Lefevre, 1986) and the acquisition of relational thinking (Skemp, 1986; $1982 ; 1976)$. In order to solve a problem, students need to gather the data in making a right decision (Setyawan et al., 2020). To acquire a better decision, perhaps mathematics classroom learning should be interactive and involve reflecting, explaining, reasoning and connecting and communicating.

\section{CONCLUSION}

To conclude, the verbalizer tend to connect the concept by using her memory about the symbols and visualizer tend to connect her imagination of a picture and represents it based on her ideas. In defining the concept of Function, both the verbalizer and visualizer connect the concept of the relation between the elements of domain to exactly one elements of codomain. In giving the examples and nonexamples of Function, the verbalizer used symbol and diagram as the representation of Function, but the visualizer only gave diagram and graph representations. The verbalizer used symbol as the representation of Function. On the other hand, the visualizer's preference is using diagram representation rather than both word and symbol representation. The verbalizer made relationship based on similarity of the symbols used, but the visualizer made relationship based on the shape of the given data. 


\section{REFERENCES}

Anam, R. S., Widodo, A., \& Sopandi, W. (2017). Representation of Elementary School Teachers on Concept of Heat Transfer. In Journal of Physics: Conf. Series (p. 895).

Blazehenkova, O., \& Kozhevnikov, M. (2008). The New Object-Spatial-Verbal Cognitive Style Model: Theory and Measurement. Applied Cognitive Psychology, 23(5), 638-663.

Dunn, R., Beaudry, J. S., \& Klavas, A. (2002). Survey of Research on Learning Styles. California Journal of Science Education, 2(2), 75-98.

Ginsburg, H. P., \& Amit, M. (2008). What is teaching mathematics to young children? A theoretical perspective and case study. Journal of Applied Developmental Psychology, 29(4), 274-285.

Hiebert, J., \& Lefevre, P. (1986). Conceptual and procedural knowledge in mathematics: An introductory analysis. In J. Hiebert (Ed.), Conceptual and Procedural Knowledge: The Case for Mathematics, 1-27. Hillsdale, New Jersey: Lawrence Erlbaum

Miles, M.B. \& Huberman, M. a. (1994). Qualitative data analysis: An expanded sourcebook (2nd ed.). Qualitative Data Analysis: An Expanded Sourcebook (2nd Ed.)., 20(1), 159-160.

National Council Of Teachers Of Mathematics. (2000). Principles and Standards for School Mathematics. School Science and Mathematics, 47(8), 868-279.

Panasuk, R. M. (2010). Three Phase Ranking Framework for Assessing Conceptual Understanding in Algebra Using Multiple Representations. Education, 131(2), 235-257.

Panasuk, R. M. (2011). Taxonomy for assessing conceptual understanding in Algebra using multiple representations. College Student Journal, 45(2), 219-232.

Setyawan, F. (2017). Profil Representasi Siswa SMP terhadap Materi PLSV Ditinjau dari Gaya Belajar Kolb. Journal of Medives: Journal of Mathematics Education IKIP Veteran Semarang, 1(2), 82-91.

Setyawan, F., \& Prahmana, R. C. I. (2017). Visualizer's representation in functions. In Journal of Physics Conference Series (Vol. 943, No. 1, p. 012004).

Setyawan, F., Prasetyo, P. W., \& Nurnugroho, B. A. (2020). Developing complex analysis textbook to enhance students' critical thinking. JRAMathEdu (Journal of Research and Advances in Mathematics Education), 5(1), 26-37.

Sierpinska, A. (2013). Understanding in Mathematics. Understanding in Mathematics.

Skemp, R. R. (1978). Relational Understanding and Instrumental Understanding. The Arithmetic Teacher, 26(3), 9-15.

Skemp, R.R. (1976). Relational understanding and instrumental understanding. Mathematics Teaching, 77, 20-26.

Skemp, R.R., (1982). The Psychology of Learning Mathematics, Great Britain: Hazell Watson \& Viney.

Skemp, R.R. (1986). The Psychology of Learning Mathematics. Great Britain: Penguin.

Wu, C.-C., Dale, N. B., \& Bethel, L. J. (1998). Conceptual models and cognitive learning styles in teaching recursion. In Proceedings of the twenty-ninth SIGCSE technical symposium on Computer science education - SIGCSE '98 (pp. 292-296).

IJEME, Vol. 4, No. 2, September 2020, 53-62 